\title{
The neuroprotection of cerebrolysin after spontaneous intracerebral hemorrhage through regulates necroptosis via Akt/ GSK3 $\beta$ signaling pathway
}

\author{
Yunna Tao ${ }^{1 \#}$ (D), Yeping $\mathrm{Xu}^{2 \#}$ (D), Meng Shen ${ }^{3 \#}$ (D), Xiaoyan Feng ${ }^{4}$, , Yan $\mathrm{Wu}^{5}$ (D), Youping $\mathrm{Wu}^{6}$ (D), \\ Liuyan Shen ${ }^{7}$ (D), Yuhai Wang ${ }^{8^{*}}$ (D)
}

1. BS. Department of Neurosurgery - Wuxi Clinical College of Anhui Medical University - $904^{\text {th }}$ Hospital of Joint Logistic Support Force of PLA - Wuxi Clinical College of Anhui Medical University - Wuxi, China.

2. BS. Department of Neurosurgery - Wuxi Clinical College of Anhui Medical University - $904^{\text {th }}$ Hospital of Joint Logistic Support Force of PLA - Wuxi Clinical College of Anhui Medical University - Wuxi, China.

3. BS. Department of Neurosurgery - Wuxi Clinical College of Anhui Medical University - $904^{\text {th }}$ Hospital of Joint Logistic Support Force of PLA - Wuxi Clinical College of Anhui Medical University - Wuxi, China.

4. BS. Department of Neurosurgery - Wuxi Clinical College of Anhui Medical University - $904^{\text {th }}$ Hospital of Joint Logistic Support Force of PLA - Wuxi Clinical College of Anhui Medical University - Wuxi, China.

5. BS. Department of Neurosurgery - Wuxi Clinical College of Anhui Medical University - $904^{\text {th }}$ Hospital of Joint Logistic Support Force of PLA - Wuxi Clinical College of Anhui Medical University - Wuxi, China.

6. BS. Department of Neurosurgery - Wuxi Clinical College of Anhui Medical University - $904^{\text {th }}$ Hospital of Joint Logistic Support Force of PLA - Wuxi Clinical College of Anhui Medical University - Wuxi, China.

7. BS. Department of Neurosurgery - Wuxi Clinical College of Anhui Medical University - $904^{\text {th }}$ Hospital of Joint Logistic Support Force of PLA - Wuxi Clinical College of Anhui Medical University - Wuxi, China.

8. MD. Department of Neurosurgery - Wuxi Clinical College of Anhui Medical University - $904^{\text {th }}$ Hospital of Joint Logistic Support Force of PLA - Wuxi Clinical College of Anhui Medical University - Wuxi, China.

\begin{abstract}
Purpose: Spontaneous intracerebral hemorrhage $(\mathrm{ICH})$ is a major cause of death and disability with a huge economic burden worldwide. Cerebrolysin (CBL) has been previously used as a nootropic drug. Necroptosis is a programmed cell death mechanism that plays a vital role in neuronal cell death after $\mathrm{ICH}$. However, the precise role of necroptosis in $\mathrm{CBL}$ neuroprotection following $\mathrm{ICH}$ has not been confirmed. Methods: In the present study, we aimed to investigate the neuroprotective effects and potential molecular mechanisms of $\mathrm{CBL}$ in $\mathrm{ICH}$-induced early brain injury (EBI) by regulating neural necroptosis in the C57BL/6 mice model. Mortality, neurological score, brain water content, and neuronal death were evaluated by terminal deoxynucleotidyl transferase dUTP nick end labeling (TUNEL) staining, Evans blue extravasation, Western blotting, and quantitative real-time polymerase
\end{abstract}

*Corresponding author: wangyuhai1516@163.com | (55 86) 13771166231

Received: June 17, 2021 | Review: Aug 15, 2021 | Accepted: Sept 16, 2021

Conflict of interest: Nothing to declare.

Research performed at Department of Neurosurgery, Wuxi Clinical College of Anhui Medical University, 904th Hospital of Joint Logistic Support Force of PLA, Wuxi Clinical College of Anhui Medical University, Wuxi, China. 
chain reaction (PCR). Results: The results show that $C B L$ treatment markedly increased the survival rate, neurological score, and neuron survival, and downregulated the protein expression of RIP1 and RIP3, which indicated that CBL-mediated inhibition of necroptosis, and ameliorated neuronal death after ICH. The neuroprotective capacity of CBL is partly dependent on the Akt/GSK3 $\beta$ signaling pathway. Conclusion: $\mathrm{CBL}$ improves neurological outcomes in mice and reduces neuronal death by protecting against neural necroptosis.

Key words: Cerebral Hemorrhage. Brain Injuries. Necroptosis. Glycogen Synthase Kinase 3 beta. Mice.

\section{Introduction}

Spontaneous intracerebral hemorrhage $(\mathrm{ICH})$ has the highest mortality rate among stroke subtypes, accounts for 15 to $20 \%$ of all stroke types, and has an increased incidence in elderly patients ${ }^{1-4}$. Acute $\mathrm{ICH}$ due to a large intracranial hematoma is associated with high morbidity and mortality, as it can lead to primary brain injury through the destruction of brain tissue and the high intracranial pressure (ICP) that results from the large hematoma ${ }^{5,6}$.

Previous studies revealed that craniotomy for hematoma evacuation is an effective therapy for limiting primary brain damage and decreasing ICP after ICH, which is of substantial interest ${ }^{5,7,8}$. However, craniotomy for hematoma evacuation cannot improve long-term outcomes and neurological recovery ${ }^{9}$. Increasing evidence shows that red blood cell debris, hemoglobin, its degradation products, and blood components trigger secondary brain injury following $\mathrm{ICH}$ and contributes to a series of damaging events, including neuroinflammation, brain edema, oxidative stress, bloodbrain barrier (BBB) damage, and neuron death ${ }^{10-15}$. In recent years, an increasing number of studies have been conducted focusing on the mechanisms underlying $\mathrm{ICH}$ induced secondary injury to search for better therapeutic targets for $\mathrm{ICH}$. The possible mechanisms underlying early brain injury (EBI) include autophagy, apoptosis, direct neuronal death, and necroptosis ${ }^{11,16,17}$.

Cerebrolysin (CBL) is a small molecule peptide extracted from the porcine brain and has been previously used as a nootropic drug ${ }^{18}$. Increasing studies have demonstrated that $\mathrm{CBL}$ administration can promote recovery of motor function, improve EBI, decrease hippocampal neuronal death in basic researches ${ }^{19-21}$. DeBoer ${ }^{19}$ reported that poststroke $\mathrm{CBL}$ administration leads to recovery of motor function regardless rehabilitative training without a protective effect on stroke volume in a stroke model. In the seizure model, $\mathrm{Kang}^{18}$ also confirmed that CBL can decrease hippocampal neuronal death after the seizure. In recent clinical studies, CBL can improve overall outcomes after moderate to severe traumatic brain injury patients ${ }^{22,23}$ and was also safe, better for early rehabilitation patients after ischemic stroke ${ }^{24}$. Although the neuroprotection of effects, CBL treatment on the $\mathrm{ICH}$ is controversial. The neuroprotective mechanisms of $\mathrm{CBL}$ are also unclear.

Necroptosis is a newly discovered pathway of regulated necrosis, a caspase-independent programmed cell death mechanism that requires the proteins RIPK3 and MLKL and is induced by death receptors ${ }^{25}$. Increasing evidence suggests that necroptosis plays a critical role in central nervous system diseases, including traumatic brain injury ${ }^{26-28}, \mathrm{ICH}^{29,30}$, ischemic stroke $^{31}$, amyotrophic lateral sclerosis, and Parkinson's and Alzheimer's disease ${ }^{32}$. The most upstream signaling activity required for the induction of necroptosis is the activation of a tumor necrosis factor (TNF) ligand family member (e.g., protein kinase function of receptor-interacting protein kinase-1-RIPK1 and mixed lineage kinase domain-like-MLKL). RIPK1 activation leads to necroptosis through the formation of a RIPK1-RIPK3 complex ${ }^{33}$. Necroptosis is common in early brain injury and may be an effective mechanism of $\mathrm{ICH}$.

In this study, we investigated the neuroprotective effect of $\mathrm{CBL}$ therapy in a mice model of $\mathrm{ICH}$, and whether the neuroprotection was dependent on the necroptosis pathway.

\section{Methods}

The study protocol was approved by the Anhui Medical University-Affiliated Wuxi Clinical College Clinical Research Ethics Committee (YXLL-2020-016).

All animal experiments performed for this study complied with the National Institutes of Health guidelines for the handling of laboratory animals and were approved by the Ethics Committee of the Wuxi Medical College of Anhui Medical University. All experiments were conducted on healthy adult male C57BL/6J mice (22-25 g) (Anhui Medical University, Hefei, China). The mice were housed in animal care facilities with a 12-h light/dark cycle and had free access to food and water.

\section{ICH animal model}

The ICH mouse model was generated based on a previously described protocol involving autologous blood 
injection $^{34}$. Briefly, male C57BL6/J mice were anesthetized by intraperitoneal (i.p.) injection of $50 \mathrm{mg} / \mathrm{kg}$ pentobarbital sodium and placed in a prone position with a stereotactic head frame. The rectal temperature was kept at $37 \pm 0.5^{\circ} \mathrm{C}$ during the operation using a heating pad. An artificial tear ointment was used to protect the eye from injury during surgery.

A midline scalp incision was made, and a cranial burr hole with a 1-mm diameter was made at the following coordinates relative to bregma: $0.2 \mathrm{~mm}$ posterior, $2.2 \mathrm{~mm}$ lateral to bregma, and $3.5 \mathrm{~mm}$ below the dura. A total of $30 \mu \mathrm{L}$ of autologous blood without anticoagulation was collected from the caudal artery and rapidly injected into the basal ganglia through the burr hole via the 26-gauge needle of a $10-\mu \mathrm{L}$ Hamilton syringe.

First, $5 \mu \mathrm{L}$ of arterial blood was injected at a depth of $2.8 \mathrm{~mm}$ from the dura (injection speed: $3 \mu \mathrm{L} / \mathrm{min}$ ). Five minutes later, the other $25 \mu \mathrm{L}$ of blood was injected at a depth of $3.5 \mathrm{~mm}$ (injection speed: $3 \mu \mathrm{L} / \mathrm{min}$ ). After the injection of autologous blood, the needle was kept in the brain for 10 min to prevent blood backflow along the needle tract. Finally, the hole was covered with medical bone wax. The animals in the Sham group received similar surgical procedures, but were injected at the same site with an equal volume of sterile saline instead of blood.

\section{Drug preparation and administration}

After the ICH model was established successfully, animals were given daily intraperitoneal injections of either CBL $(2.5 \mathrm{~mL} / \mathrm{kg} /$ day, no dilution; EBEWE Arzneimittel, Austria) or plain (control) saline for 72 hours. Figure 1a summarizes the timeline of the experimental protocol of the study. We administered Ly294002 (2-(4-morpholinyl)-8phenyl-4H-1-benzopyran-4-one) (Cell Signaling Technology, United States of America), which is a highly selective inhibitor of PI3K. Anesthetized mice were positioned in a stereotaxic frame, and Ly294002 (50 mmol in 25\% dimethyl sulfoxide and phosphate-buffered saline-PBS) was injected intracerebroventricularly $(10 \mathrm{~mL}$, bregma; $1.4 \mathrm{~mm}$ lateral, $0.8 \mathrm{~mm}$ posterior, $3.6 \mathrm{~mm}$ deep) with a syringe pump 30 minutes before $\mathrm{ICH}$.

\section{Neurobehavioral assessment}

The severity of brain injury was evaluated by determining neurological function 72 hours after ICH using our previously described neurological grading system. The neurological scores ranged from 3 to 18 and included spontaneous activities (0-3), movement symmetry of all limbs (0-3), forelimb outstretching (0-3), body proprioception (1-3), response to vibrissae touch (1-3), and climbing (1-3). All mice from every group received a behavioral assessment, and a higher score represented better neurological function.

\section{Brain water-content measurement}

The severity of brain edema was evaluated by measuring the brain water content using the standard wet-dry method, as previously reported ${ }^{16,35,36}$. The mice were sacrificed 72 hours after $\mathrm{ICH}$, and the entire brain was harvested and separated into the ipsilateral and contralateral cortex, ipsilateral and contralateral basal ganglia, and cerebellum (wet weight). Then, brain specimens from each group were dehydrated at $105^{\circ} \mathrm{C}$ for $24 \mathrm{~h}$ to acquire the dry weight. The percentage of brain water content was equal to (wet weight - dry weight)/wet weight $\times 100 \%$.

\section{Evans blue extravasation}

Evans blue extravasation was performed as previously described $^{37}$. Briefly, mice were anesthetized by pentobarbital sodium (50 mg/kg) injection $72 \mathrm{~h}$ after $\mathrm{ICH}$. Evans blue dye $(2 \%, 5 \mathrm{~mL} / \mathrm{kg}$; Sigma-Aldrich, St. Louis, MO, United States of America) was injected into the left femoral vein over $2 \mathrm{~min}$ and circulated for $60 \mathrm{~min}$. Then, the mice were sacrificed with $100 \mathrm{mg} / \mathrm{kg}$ sodium pentobarbital via intraperitoneal injection and with PBS intracardial perfusion. Death was clarified by observing respiration and by using the corneal reflection method. The brains were removed and quickly divided into the left and right cerebral hemispheres, weighed, homogenized in saline, and centrifuged at 10,000 rpm for $30 \mathrm{~min}$. Subsequently, the resultant supernatant was added with an equal volume of trichloroacetic acid, incubated overnight at $4^{\circ} \mathrm{C}$, and centrifuged at 10,000 rpm for $30 \mathrm{~min}$. Next, the resultant supernatant was collected and spectrophotometrically quantified at $610 \mathrm{~nm}$ for Evans blue dye.

\section{TUNEL staining}

A terminal deoxynucleotidyl transferase dUTP nick end labeling (TUNEL) assay was conducted to assess neuronal death in the hippocampus. TUNEL reaction mixture $(50 \mu \mathrm{L})$ was added to each sample, and the slides were incubated in a humidified dark chamber for $60 \mathrm{~min}$ at $37^{\circ} \mathrm{C}$. The slides were then incubated with 4',6-diamidino-2-phenylindole (DAPI) for 5 minutes at room temperature in the dark to stain the nuclei, followed by imaging with a fluorescence microscope. The procedure was performed according to the manufacturer's instructions with a TUNEL staining kit. A negative control (without the TUNEL reaction mixture) was used. The cell count was confirmed in four randomly selected high-power fields, and the data obtained from each field were averaged.

\section{Quantitative real-time PCR}

Quantitative real-time polymerase chain reaction (qPCR) analysis was performed as indicated previously ${ }^{38}$. Total RNA was extracted from either cell cultures or hippocampal 
brain samples using TRIzol reagent (Gibco; Thermo Fisher Scientific, Inc., Waltham, MA, United States of America) according to the manufacturer's instructions. Then, RNA was reverse transcribed to complementary DNA (cDNA) using the RevertAid First Strand cDNA Synthesis Kit (K1622; Thermo Fisher Scientific Inc., Rockford, IL, United States of America). ATF4 and CHOP mRNA levels in each sample were measured by qPCR using SYBR Green Master Mix (Toyobo Co., Ltd., Osaka, Japan). Glyceraldehyde 3-phosphate dehydrogenase (GAPDH) was used as an internal control. The qPCR thermocycling conditions were as follows: 45 (2 $\mathrm{min})$ and $95^{\circ} \mathrm{C}(10 \mathrm{~min})$, followed by 40 cycles of denaturation at $95^{\circ} \mathrm{C}(15 \mathrm{sec})$, annealing at $60^{\circ} \mathrm{C}(1 \mathrm{~min})$, and extension at $72^{\circ} \mathrm{C}$ (1 min). All samples were analyzed in triplicate.

\section{Western blot analysis}

Western blot analysis was performed as indicated previously ${ }^{36}$. Briefly, cerebral cortex samples or cell homogenates were collected, dissolved, and separated by sodium dodecyl sulfate-polyacrylamide gel electrophoresis in $10 \%$ polyacrylamide gels. A BCA Protein Assay Kit (Beyotime) was used to measure protein concentrations by the bicinchoninic acid method. Then, protein samples were transferred onto immobilon nitrocellulose membranes.

The membranes were blocked at room temperature for $1 \mathrm{~h}$ with $5 \%$ nonfat milk and then incubated with the following primary antibodies overnight at $4^{\circ} \mathrm{C}$ : rabbit anti- $\beta$-actin (1:1,000, rabbit polyclonal, Abcam, ab8227), rabbit anti-claudin-5 (1:1,000, rabbit monoclonal, Abcam, ab131259), rabbit ZO-1 (1:1,000, rabbit polyclonal, Abcam, ab 96587), rabbit anti-RIP1 (1:1,000; rabbit polyclonal; Abcam; cat. no. ab106393), rabbit anti-RIP3 (1:1,000; rabbit polyclonal; Abcam; cat. no. ab62344), rabbit anti-AKT (phospho S473) (1:1,000, rabbit monoclonal, Abcam, ab81283), and rabbit anti- Anti-GSK3 $\beta$ (phospho S9) (1:1,000, rabbit monoclonal, Abcam, ab75814).

After washing the membranes with tris-buffered saline with Tween (TBST) three times, HRP-conjugated goat antirabbit IgG or goat anti-mouse IgG secondary antibodies $(1: 5,000)$ were applied, and the membranes were incubated in the secondary antibodies at room temperature for $1.5 \mathrm{~h}$. The protein bands were detected using a Bio-Rad imaging system (Bio-Rad, Hercules, CA, United States of America) and quantified with ImageJ.

\section{Statistical analysis}

All experiments were repeated more than three times, and the data are expressed as the means and scanning electron microscope (SEM). Statistical Package for the Social Sciences (SPSS) 14.0 (SPSS, Chicago, IL, United States of America) and GraphPad Prism 6 (GraphPad Software, San Diego, CA, United
States of America) were used for the statistical analyses. Student's t-test was used if two groups were compared, and one-way analysis of variance (ANOVA) followed by Bonferroni's post hoc test was used for the comparison of two independent variables. For nonnormally distributed data and/or non-homogeneous variance, we used the Kruskal-Wallis test followed by Dunn's post hoc test. For all the statistical analyses, data were considered significant at $p<0.05$.

\section{Results}

\section{The effects of mortality and neurological function in the $\mathrm{ICH}$ models}

We constructed the $\mathrm{ICH}$ model and the $\mathrm{CBL}$ treatment after ICH (Fig. 1a). We evaluated the effect of CBL treatment on long-term neurological damage parameters, including mortality rates and neurological scores. As shown in Fig. 1, mortality rates (Fig. 1b) were decreased in the $\mathrm{ICH}+\mathrm{CBL}$ group, but no significant difference compared with the $\mathrm{ICH}$ group (odds ratio-OR $=0.308,95 \%$ prediction interval95\%PI 0.049-1.928). Neurological scores were decreased significantly after $\mathrm{ICH}$, and CBL treatment could significantly increase the neurological scores $(p<0.05)$ (Fig. 1c).

(a)

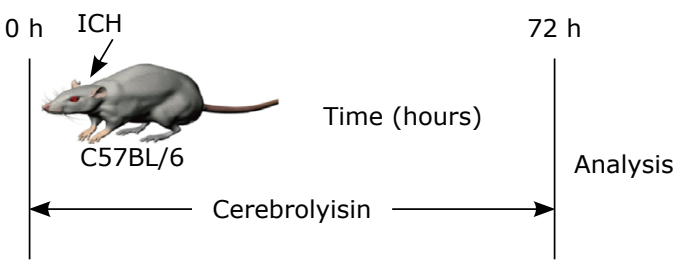

(b)

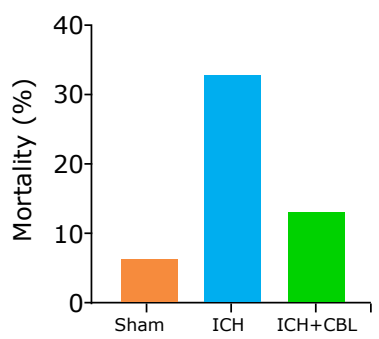

(c)

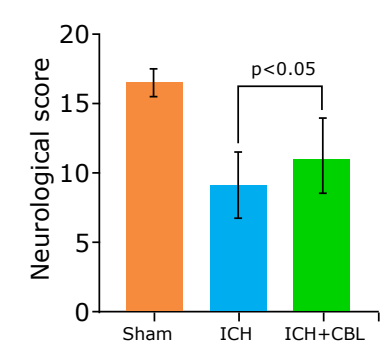

$\mathrm{ICH}$ : spontaneous intracerebral hemorrhage; $\mathrm{CBL}$ : cerebrolysin; ANOVA: analysis of variance; SEM: scanning electron microscope.

Figure 1 - The effects of mortality and neurological function in the ICH models. (a) Schematic of experimental paradigm for modeling $\mathrm{ICH}$ in mice. (b) The mortality rates were increased in the $\mathrm{SAH}$ group, and decreased after CBL treatment, but no significant difference compared with the ICH group. (c) Neurological score of mice in Sham group, $\mathrm{ICH}$ group, and $\mathrm{ICH}+\mathrm{CBL}$ group at $72 \mathrm{~h}$ after ICH $(n=10, p<0.05)$. ANOVA; mean \pm SEM. 


\section{CBL alleviates brain edema and BBB permeability after ICH}

To clarify the $\mathrm{EB}$ after $\mathrm{ICH}$, we used brain water content by the wet-dry method at $72 \mathrm{~h}$ after ICH to evaluate brain damage. The results showed that ICH increased the brain water content significantly, which was alleviated after CBL treatment (Fig. 2a). Similar results in BBB permeability, which were increased significantly after ICH, and CBL administration could significantly alleviate BBB permeability (Fig. 2b).

To further clarify the BBB integrity, we detected the expression levels of Zonula occludens-1 (ZO-1) and Claudin 5 by Western blotting (Fig. 2c). The Western blotting results showed that the expression of tight junction proteins (Fig. 2 d-e) significantly decreased after ICH ( $p<0.05$ vs. control group), suggesting that $\mathrm{ICH}$-induced alterations in tight junction proteins may be responsible for the increased BBB permeability. Meanwhile, CBL treatment markedly alleviated this decrease at $72 \mathrm{~h}\left({ }^{*} \mathrm{p}<0.05 v\right.$ s. ICH group).

\section{CBL alleviates hippocampus neuron necroptosis after ICH}

Our previous study has indicated that necroptosis plays a vitally important role in early brain injury ${ }^{27}$. Therefore, the present study also investigated whether CBL improves brain injury after ICH via regulating neuron necroptosis.

First, the mRNA expression levels of the necroptosisrelated genes RIP1 and RIP3 in the hippocampus were determined by real time qPCR. As expected, the mRNA expression levels of RIP1 and RIP3 mRNA increased after ICH and decreased after CBL treatment (Fig. 3 a-b). (a)

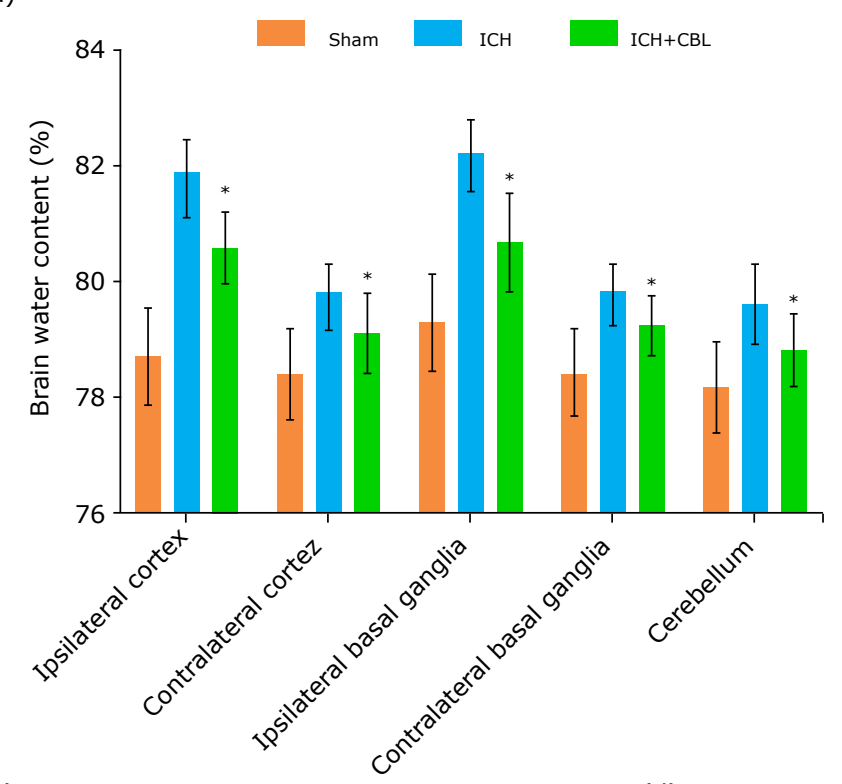

(c)

(d)

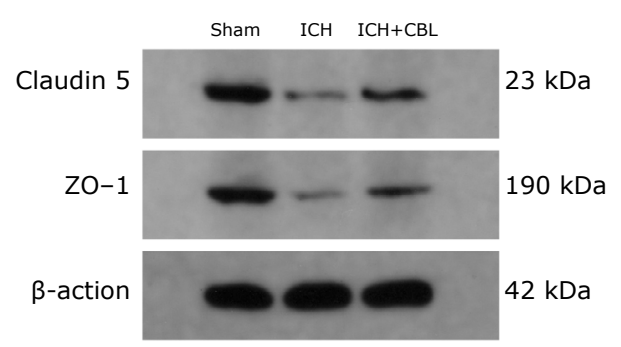

(b)

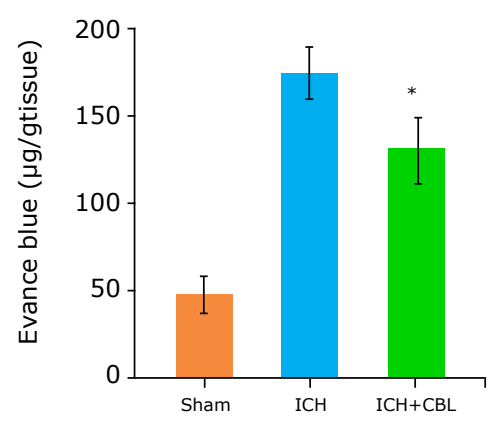

(e)

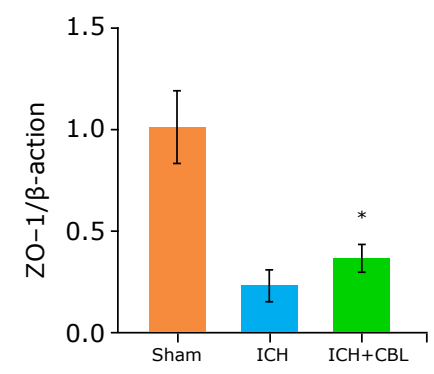

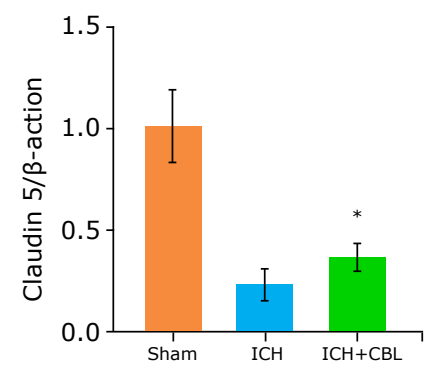

$\mathrm{ICH}$ : spontaneous intracerebral hemorrhage; CBL: cerebrolysin; BBB: blood brain-barrier; ANOVA: analysis of variance; SEM: scanning electron microscope.

Figure 2 - CBL alleviates brain edema and BBB permeability after ICH. (a) CBL alleviates brain water content after ICH. (b) $\mathrm{CBL}$ alleviates BBB permeability after ICH. (c) Expression of ZO-1 and Claudin 5 in the brain cortex of mice after ICH were determined by Western blotting. (d-e) Quantification of ZO-1 and Claudin 5 in the brain cortex to $\beta$-actin loading control, CBL increased ZO-1 and Claudin 5 expression after ICH in mice ( $n=5, * p<0.05$ vs. ICH group; ANOVA; mean \pm SEM). 
(a)

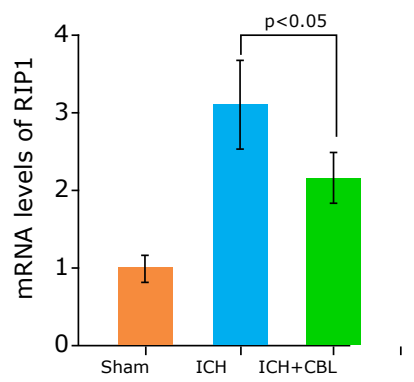

(d)

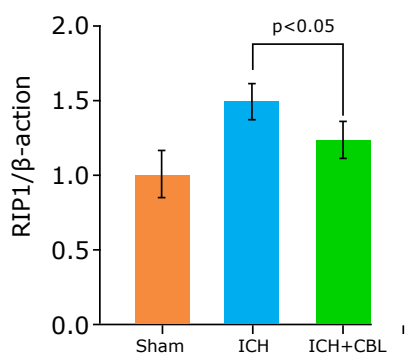

(b)

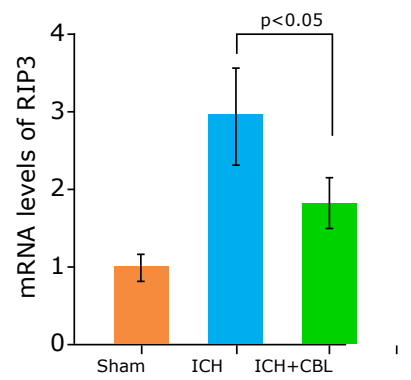

(c)

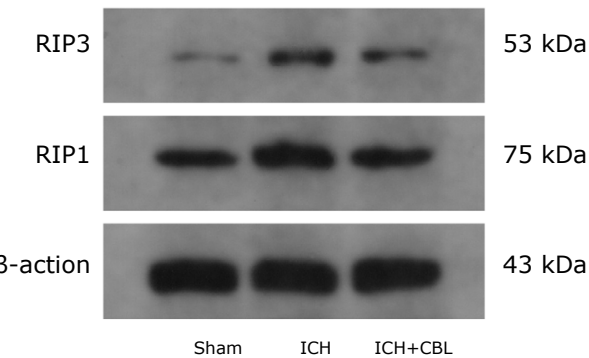

(e)

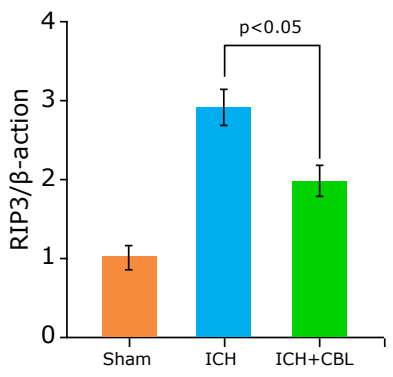

(f)

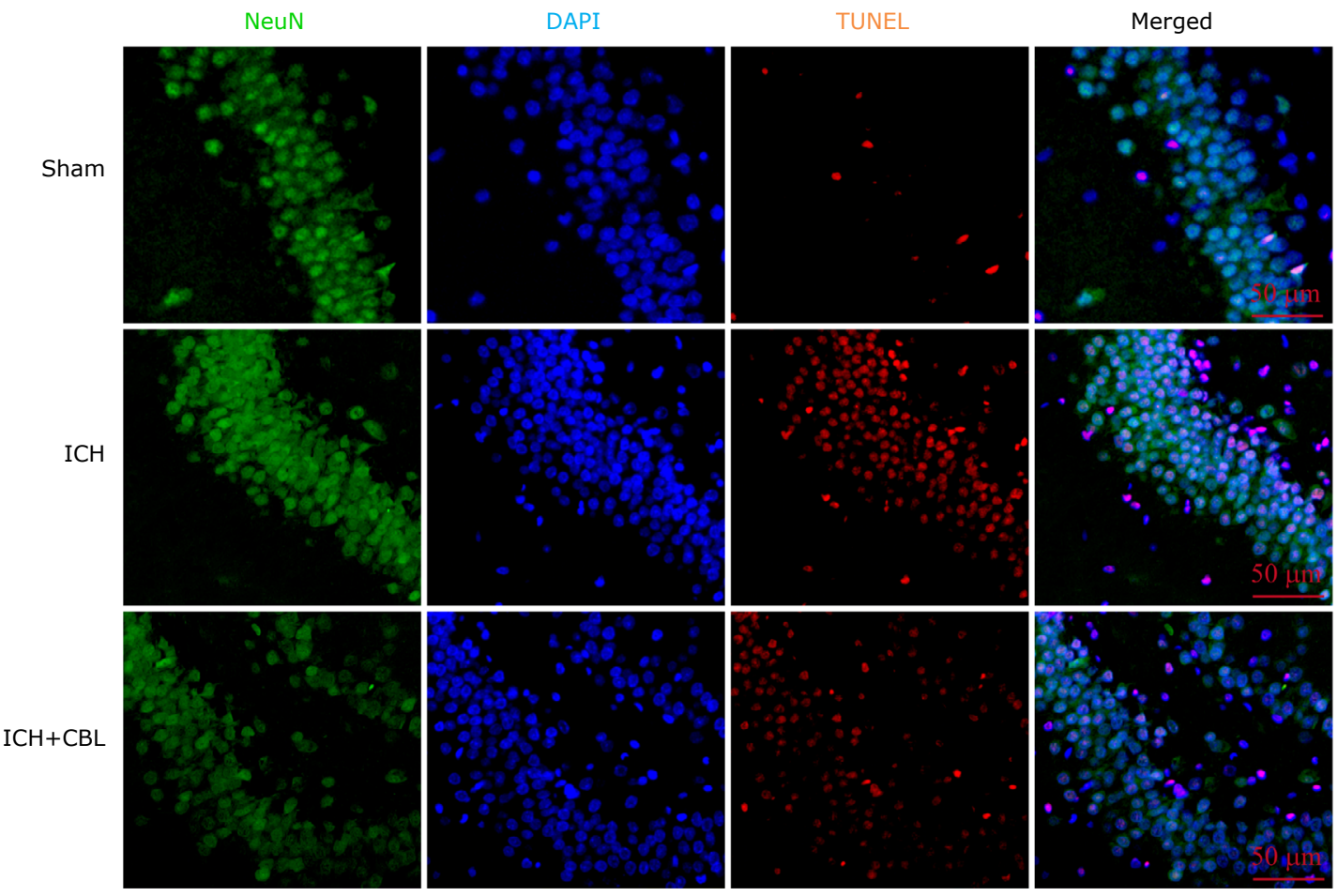

ICH: spontaneous intracerebral hemorrhage; CBL: cerebrolysin; PCR: polymerase chain reaction; ANOVA: analysis of variance; SEM: scanning electron microscope; DAPI: 4',6-diamidino-2-phenylindole; TUNEL: terminal deoxynucleotidyl transferase dUTP nick end labeling.

Figure 3 - CBL alleviates hippocampus neuron necroptosis after ICH. (a) mRNA expression of RIP1 in the hippocampus of mice after ICH were determined by real-time PCR, CBL decreased the mRNA expression of RIP1 after ICH significantly. (b) CBL decreased the mRNA expression of RIP3 after ICH significantly. (c) Expression of RIP1 and RIP3 in the hippocampus of mice after ICH were determined by Western blotting. (d-e) Quantification of RIP1 and RIP3 in the hippocampus to $\beta$-actin loading control, CBL decreased hippocampus RIP1 and RIP3 expression after ICH significantly. (f) TUNEL staining, CBL alleviates neuronal death in the hippocampus $72 \mathrm{~h}$ after ICH. Representative images of apoptotic neurons are shown. $p<0.05$. Scale bar=50 $\mu \mathrm{m}$. ANOVA; mean \pm SEM; DAPI; TUNEL. 
The protein expression levels of RIP1 and RIP3 in the hippocampus were also measured by Western blotting analysis (Fig. 3c). The results were similar to the mRNA analysis results (Fig. 3 d-e). Importantly, to further clarify the hippocampus neuron death after ICH, we used TUNEL assay to quantify the level of cell death in treated and untreated $\mathrm{ICH}$ mice at $72 \mathrm{~h}$ after model construction. As we expected, our results indicated more hippocampus neuron death after $\mathrm{ICH}$, while decreased significantly after $\mathrm{CBL}$ treatment (Fig. 3f). Hence, these data showed that $\mathrm{CBL}$ can alleviate hippocampus neuron necroptosis after ICH.

\section{$C B L$ maybe regulates necroptosis by $A k t / G S K 3 \beta$ signaling pathway after ICH}

Our previous study had demonstrated that necroptosis plays a key role in the pathogenesis of neuronal death after traumatic brain injury ${ }^{26}$. Then, we also detected the protein expression levels of Akt and GSK3 $\beta$ phosphorylation by Western blotting (Fig. 4a). The results showed that the expression levels of Akt and GSK3 $\beta$ phosphorylation were increased significantly in the ICH group and decreased after CBL administration (Fig. 4 b-c). Thus, these results showed that $\mathrm{CBL}$ may be inhibited $\mathrm{SAH}$-induced necroptosis by regulated Akt/GSK3 $\beta$ signaling pathway.

\section{Ly294002 reversed the neuroprotection of CBL}

To further explore the role of the Akt/GSK3 $\beta$ signaling pathway after $\mathrm{CBL}$ administration in the $\mathrm{EBI}$ after $\mathrm{ICH}$. Ly294002, a highly specific PI3K inhibitor, can prevent phosphorylation of Akt and GSK3 $\beta$. We infused Ly294002 into the left lateral ventricle of mice. The results showed that the behavioral scores and brain edema were improved after CBL treatment, while they were partially prevented by Ly294002 (Fig. 5 a-b). The expression levels of necroptosisrelated protein (RIP1 and RIP3) also were decreased after Ly294002 treatment, and this effect was alleviated after Ly294002 (Fig. 5 c-e). We also performed TUNEL staining in brain sections (Fig. 5f), and the results showed that the anti-necroptosis role of CBL was partially inhibited by Ly294002.

(a)

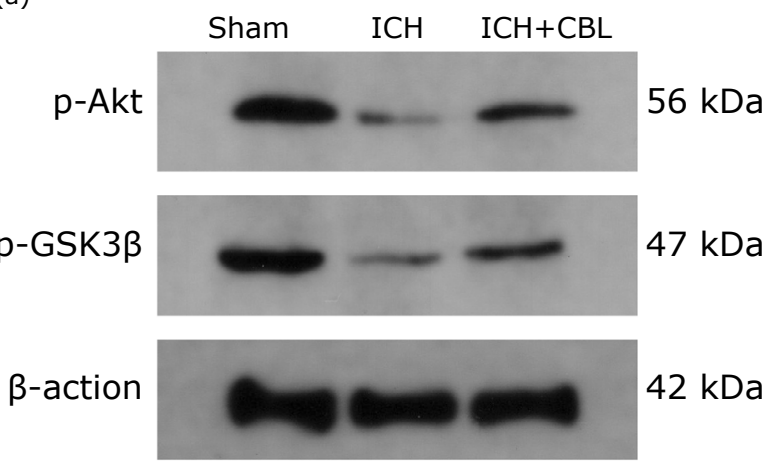

(b)

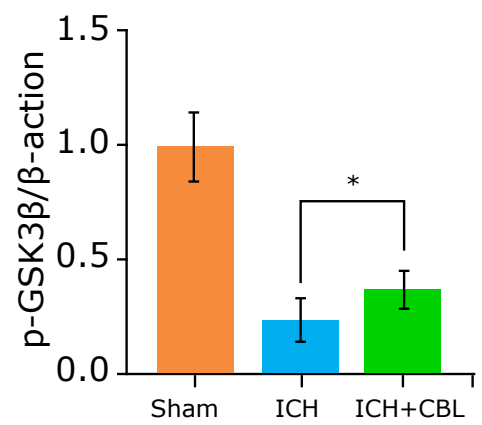

(c)

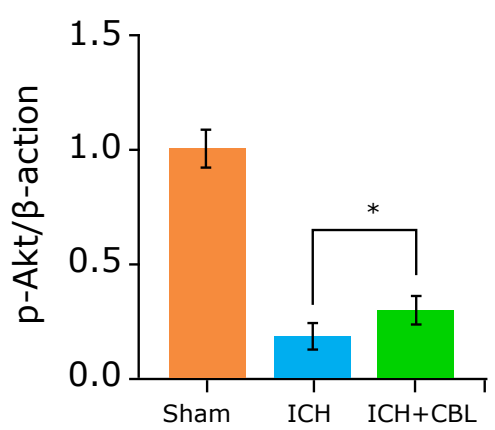

CBL: cerebrolysin; ICH: spontaneous intracerebral hemorrhage; PCR: polymerase chain reaction; ANOVA: analysis of variance; SEM: scanning electron microscope.

Figure 4 - CBL maybe regulates necroptosis by Akt/GSK3 $\beta$ signaling pathway after ICH. (a) Expression of Akt and GSK3 $\beta$ in the brain cortex after ICH were determined by Western blotting. (b-c) Quantification of Akt and GSK3 $\beta$ in the brain cortex to $\beta$-actin loading control, CBL increased brain cortex Akt and GSK3 $\beta$ expression after ICH significantly. ${ }^{*} p<0.05$; ANOVA; mean \pm SEM. 
(a)

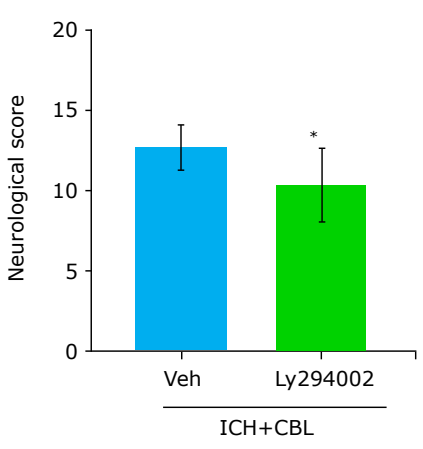

(c)

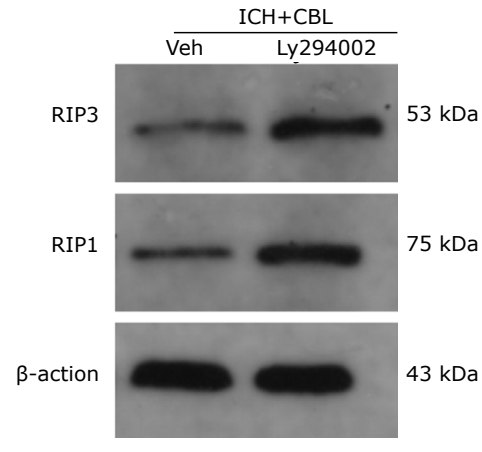

(f)

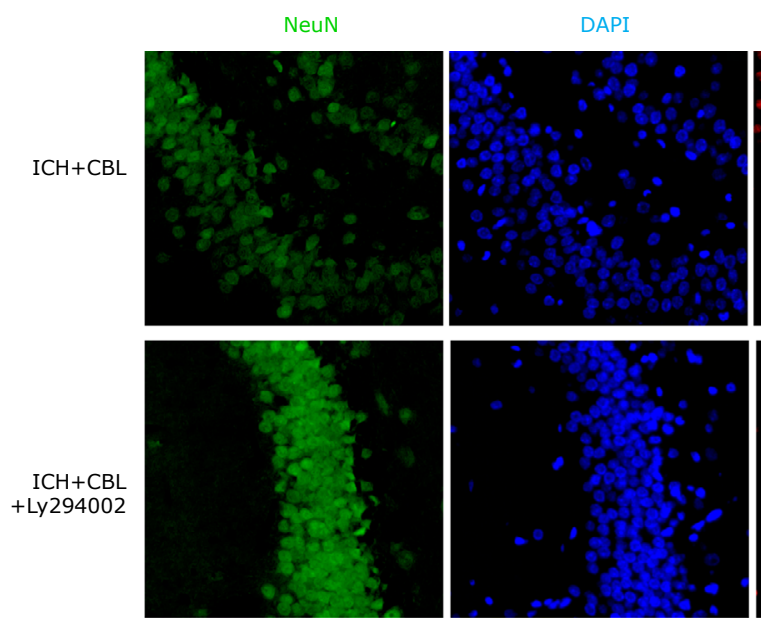

(b)

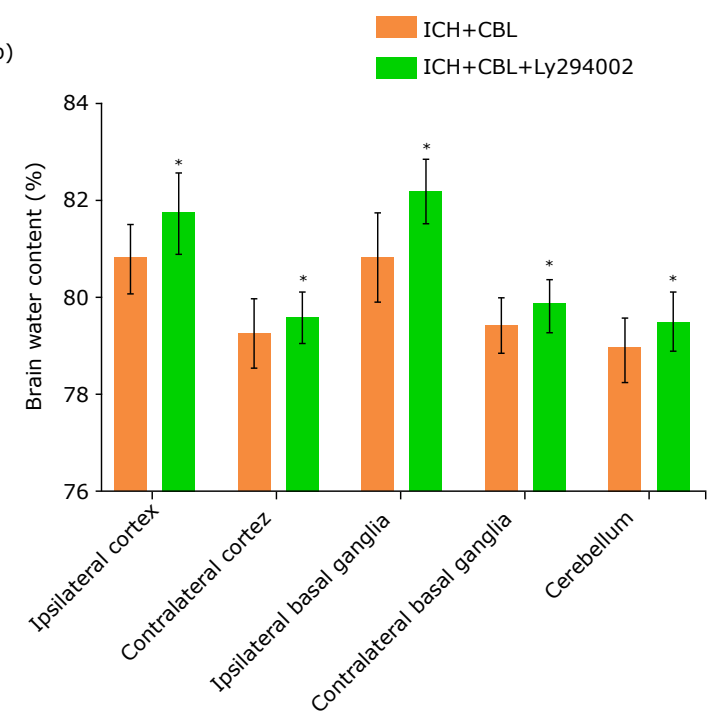

(d)

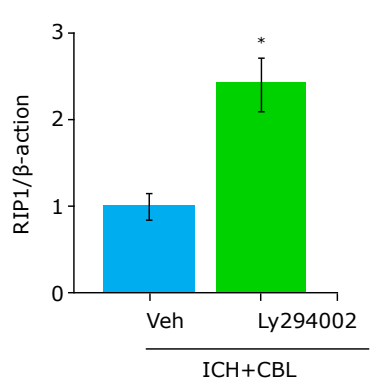

(e)

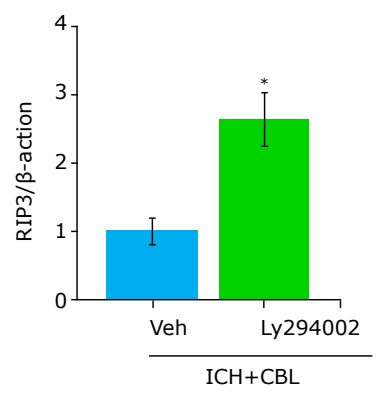

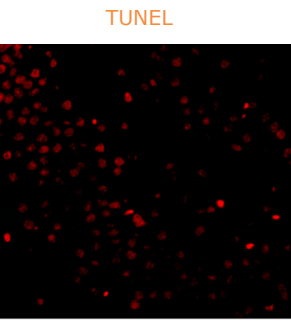
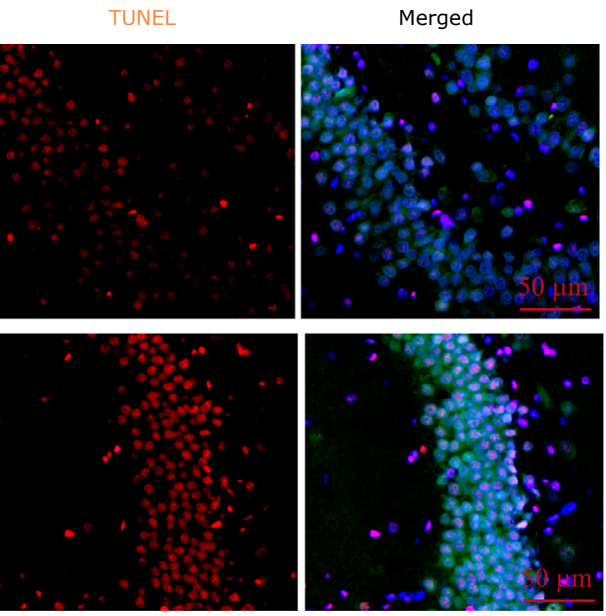

ICH: spontaneous intracerebral hemorrhage; CBL: cerebrolysin; DAPI: 4',6-diamidino-2-phenylindole; TUNEL: terminal deoxynucleotidyl transferase dUTP nick end labeling; ANOVA: analysis of variance; SEM: scanning electron microscope.

Figure 5 - Ly294002 reversed the neuroprotection of CBL. (a) PI3K inhibitor, Ly294002 decreased the neurological score significantly at $72 \mathrm{~h}$ after ICH to compare with ICH group. (b) Ly294002 increased the brain water content significantly. (c) Expression of RIP1 and RIP3 in the hippocampus of mice after ICH were determined by Western blotting. (d-e) Quantification of RIP1 and RIP3 in the hippocampus to $\beta$-actin loading control, Ly294002 increased hippocampus RIP1 and RIP3 expression after ICH significantly. (f) TUNEL staining, Ly294002 increased neuronal death in the hippocampus $72 \mathrm{~h}$ after ICH, representative images of apoptotic neurons are shown. Scale bar $=50 \mu \mathrm{m} ;{ }^{*} \mathrm{p}<0.05 \mathrm{vs}$. ICH+CBL group; ANOVA; mean \pm SEM. 


\section{Discussion}

Here, we evaluated the therapeutic potential of CBL for alleviating early brain injury in a mouse in the SAH model. The present study demonstrated that CBL was a neuroprotective agent that can attenuate early brain injury following SAH. We found that CBL can improve neurological dysfunction after SAH; CBL can alleviate brain edema and BBB permeability after $\mathrm{SAH} ; \mathrm{CBL}$ can prevent necroptosis and alleviate neuronal death after $\mathrm{SAH}$; and the anti-necroptosis roles of CBL may be related to the Akt/GSK3 $\beta$ signaling pathway.

$\mathrm{CBL}$ is an intravenously administered small molecule peptide extracted from the porcine brain, composed of approximately $15 \%$ low molecular weight peptides and $85 \%$ amino acids in an aqueous solution and has been previously used as a nootropic drug ${ }^{39}$. It is a brain-specific pleiotropic agent that is proposed to target multiple pathways to improve functional recovery after neurological diseases and injuries in many central nervous system diseases ${ }^{18-22}$.

Satou et al. ${ }^{40}$ reported that CBL can promote neurite outgrowth and cholinergic fiber regeneration in vitro. Guan et al. ${ }^{41}$ also demonstrated that CBL can alleviate brain injury after focal cerebral ischemia by regulating neuroinflammation. The related molecular mechanisms partly via the activation of CREB/PGC-1 $\alpha$ pathway play an important therapeutic role as anti-neuroinflammatory agents. In the spontaneously hypertensive rats with hyperglycemia model, CBL also can alleviate the reduction in the number of dendritic spines in the prefrontal cortex and hippocampus ${ }^{42}$.

In the clinical studies, Muresanu et al..$^{22}$ reported that CBL treatment is effective and safe for moderate to severe traumatic brain injury patients by a phase IIIb/IV singlecenter, prospective, randomized, double-blind, placebocontrolled clinical trial with 142 patients. An observational retrospective clinical study about patients also confirmed that CBL may improve the level of consciousness in stroke patients with a minimally conscious state ${ }^{43}$.

In the aneurysmal subarachnoid hemorrhage clinical retrospectively study, $\mathrm{CBL}$ injection during the acute period of SAH appeared to reduce the mortality rate, especially in poor-grade patients ${ }^{44}$, while a recent randomized, placebocontrolled, double-blind, pilot trial demonstrated that daily $\mathrm{CBL}$ ( $30 \mathrm{~mL} /$ day) is safe, well-tolerated, and feasible for SAH patients, but it does not improve the six-month global functional performance of patients $\mathrm{s}^{45}$. In the present study, we found that CBL can improve early brain injury by alleviating brain edema and neuron necroptosis after SAH.

Necroptosis is a newly discovered pathway of regulated necrosis, a caspase-independent programmed cell death mechanism that requires the proteins RIPK3 and MLKL and is induced by death receptors ${ }^{25}$. Necroptotic cells display disrupted plasma membrane and cell lysis and can be observed in a variety of cell types, including neurons ${ }^{27}$. The most upstream signaling activity required a TNF ligand family member RIPK1 activation and led to necroptosis through the formation of a RIPK1-RIPK3 complex ${ }^{33}$.

Our previous study also demonstrated that necroptotic cell death might play an important role in traumatic neuronal injury-induced cell death and Si-Arc-induced aggravation of neuronal damage ${ }^{27}$.

Shen also reported that necroptosis is an important mechanism of cell death in brain injury after ICH, and inhibition of necroptosis may be a potential therapeutic intervention of ICH. Phosphorylation of RIP1 is the key molecular mechanism of necroptosis, which was activated in the in-vitro model of $\mathrm{ICH}^{30}$. Lu et al. ${ }^{46}$ also indicated that microglial necroptosis is the main reason to lead brain injury in the pathogenesis of $\mathrm{ICH}$. The potential mechanisms may be RIP3-mediated necroptosis by regulating the deubiquitinating enzyme A20 (also known as TNFAIP3) expression.

Our study also revealed that the protein and mRNA expression levels of RIPK1 and RIPK3 were elevated $72 \mathrm{~h}$ after the $\mathrm{ICH}$ procedure, and CBL decreased the expression of RIPK1 and RIPK3.

The regulated mechanisms of necroptosis are extremely complicated. In the present study, we found that the antinecroptosis role of CBL may be related to the Akt/GSK3 $\beta$ signaling pathway. Chen et al. ${ }^{26}$ reported that phosphorylation of Akt and GSK3 $\beta$ can regulate necroptosis after traumatic brain injury, and Akt inhibitor LY294002 partially reversed the protective effects of perampanel. Chen et al. ${ }^{47}$ demonstrated that methylene blue can inhibit apoptosis and ameliorate neuroinflammation after ICH via activating the PI3K/Akt/ GSK3 $\beta$ pathway. A recent study also indicated that $A k t / p-$ GSK $\beta / \beta$-catenin pathways play a very important role in the $\mathrm{ICH}$. However, to date, there are no reports about the regulation of Akt/GSK3 $\beta$ on RIP1 activation, the exact mechanism of which needs to be further determined.

\section{Conclusions}

Our study provided evidence that necroptosis, which is mediated by the RIP1 and RIP3, has been emerging as an important cellular regulatory mechanism and contributes to early brain injury after ICH. In this study, for the first time, we reported that $\mathrm{CBL}$-induced regulation of necroptosis by Akt/GSK3 $\beta$ pathway and also provides a new idea to explore the biological effects and underlying anti-necroptosis and neuroprotection mechanisms of the CBL.

\section{Author's contribution}

Conception of the study: Tao $Y, X u Y$, Shen $M$ and Wang $Y$; Conception and design of the study: Tao $Y, W u$ Yan, Wu 
$Y$, Shen $L$ and Wang $Y$; Acquisition and interpretation of data: Tao $Y$ and Feng $X$; Manuscript writing: Tao $Y, X u Y$, Shen $M$ and Wang Y; Critical revision: Tao Y, Xu Y, Shen M and Wang $Y$; Final approval of the version to be published: Tao $Y, X u Y$, Shen $M$, Feng $X$, Wu Yan, Wu Y, Shen $L$ and Wang $Y$. \#The authors contributed equally to this work.

\section{Data availability statement}

Data will be available upon request.

\section{Funding}

National Natural Science Foundation of China

https://doi.org/10.13039/501100001809

Grant no 81871589

Wuxi Municipal Bureau on Science and Technology

https://doi.org/10.13039/501100008109

Grant n N20201008

\section{Acknowledgments}

Not applicable.

\section{References}

1. Zhang $Y$, Zhang $X$, Wei Q, Leng S, Li C, Han B, Bai Y, Zhang $\mathrm{H}$, Yao $\mathrm{H}$. Activation of sigma-1 receptor enhanced pericyte survival via the interplay between apoptosis and autophagy: implications for blood-brain barrier integrity in stroke. Transl Stroke Res. 2020;11(2):267-87. https://doi. org/10.1007/s12975-019-00711-0

2. Zhang Z, Cho S, Rehni AK, Quero HN, Dave KR, Zhao W. Automated assessment of hematoma volume of rodents subjected to experimental intracerebral hemorrhagic stroke by bayes segmentation approach. Transl Stroke Res. 2020;11(4):789-98. https://doi.org/10.1007/ s12975-019-00754-3

3. Gross BA, Jankowitz BT, Friedlander RM. Cerebral intraparenchymal hemorrhage: a review. JAMA. 2019;321(13):1295-303. https://doi.org/10.1001/ jama.2019.2413

4. Chen J, Zhu J, He J, Wang Y, Chen L, Zhang C, Zhou J, Yang L. Ultra-early microsurgical treatment within $24 \mathrm{~h}$ of SAH improves prognosis of poor-grade aneurysm combined with intracerebral hematoma. Oncol Lett. 2016;11(5):31738. https://doi.org/10.3892/ol.2016.4327

5. Wu X, Luo J, Liu H, Cui W, Guo K, Zhao L, Bai H, Guo W, Guo $H$, Feng D, Qu Y. Recombinant adiponectin peptide ameliorates brain injury following intracerebral hemorrhage by suppressing astrocyte-derived inflammation via the inhibition of drp1-mediated mitochondrial fission. Transl Stroke Res. 2020;11(5):924-39. https://doi.org/10.1007/ s12975-019-00768-x
6. Hanley DF, Thompson RE, Rosenblum M, Yenokyan G, Lane K, McBee N, Mayo SW, Bistran-Hall AJ, Gandhi D, Mould WA, Ullman N, Ali $H$, Carhuapoma JR, Kase CS, Lees KR, Dawson J, Wilson A, Betz JF, Sugar EA, Hao Y, Avadhani R, Caron JL, Harrigan MR, Carlson AP, Bulters D, LeDoux D, Huang J, Cobb C, Gupta G, Kitagawa R, Chicoine MR, Patel H, Dodd R, Camarata PJ, Wolfe $S$, Stadnik A, Money PL, Mitchell P, Sarabia R, Harnof $S$, Barzo P, Unterberg A, Teitelbaum JS, Wang W, Anderson CS, Mendelow AD, Gregson B, Janis S, Vespa P, Ziai W, Zuccarello $M$, Awad IA. Efficacy and safety of minimally invasive surgery with thrombolysis in intracerebral haemorrhage evacuation (MISTIE III): a randomised, controlled, open-label, blinded endpoint phase 3 trial. Lancet. 2019;393(10175):1021-32. https://doi. org/10.1016/s0140-6736(19)30195-3.

7. Chen J, Wang Y, Wu J, Yang J, Li M, Chen Q. The potential value of targeting ferroptosis in early brain injury after acute CNS disease. Front Mol Neurosci. 2020;13:110. https://doi.org/10.3389/fnmol.2020.00110

8. Adeoye O, Broderick JP. Advances in the management of intracerebral hemorrhage. Nat Rev Neurol. 2010;6(11):593601. https://doi.org/10.1038/nrneurol.2010.146

9. Mendelow AD, Gregson BA, Rowan EN, Murray GD, Gholkar A, Mitchell PM. Early surgery versus initial conservative treatment in patients with spontaneous supratentorial lobar intracerebral haematomas (STICH II): a randomised trial. Lancet. 2013;382(9890):397-408. https://doi. org/10.1016/s0140-6736(13)60986-1

10. Bao WD, Zhou XT, Zhou LT, Wang F, Yin X, Lu Y, Zhu LQ, Liu D. Targeting miR-124/Ferroportin signaling ameliorated neuronal cell death through inhibiting apoptosis and ferroptosis in aged intracerebral hemorrhage murine model. Aging Cell. 2020;19(11):e13235. https://doi. org/10.1111/acel.13235

11. Chen JH, Yang LK, Chen L, Wang YH, Wu Y, Jiang BJ, Zhu J, Li PP. Atorvastatin ameliorates early brain injury after subarachnoid hemorrhage via inhibition of AQP4 expression in rabbits. Int J Mol Med. 2016;37(4):1059-66. https://doi.org/10.3892/ijmm.2016.2506

12. Gautam J, Xu L, Nirwane A, Nguyen B, Yao Y. Loss of mural cell-derived laminin aggravates hemorrhagic brain injury. J Neuroinflammation. 2020;17(1):103. https://doi. org/10.1186/s12974-020-01788-3

13. Karuppagounder SS, Alim I, Khim SJ, Bourassa MW, Sleiman SF, John R, Thinnes CC, Yeh TL, Demetriades M, Neitemeier S, Cruz D, Gazaryan I, Killilea DW, Morgenstern L, Xi G, Keep RF, Schallert T, Tappero RV, Zhong J, Cho S, Maxfield FR, Holman TR, Culmsee C, Fong GH, Su Y, Ming GL, Song H, Cave JW, Schofield CJ, Colbourne F, Coppola G, Ratan RR. Therapeutic targeting of oxygen-sensing prolyl hydroxylases abrogates ATF4dependent neuronal death and improves outcomes after brain hemorrhage in several rodent models. Sci Transl Med. 2016;8(328):328ra29. https://doi.org/10.1126/ scitransImed.aac6008 
14. Xue $M$, Yong VW. Neuroinflammation in intracerebral haemorrhage: immunotherapies with potential for translation. Lancet Neurol. 2020;19(12):1023-32. https:// doi.org/10.1016/s1474-4422(20)30364-1

15. ZhouY,WangY,WangJ,AnneStetlerR, YangQW.Inflammation in intracerebral hemorrhage: from mechanisms to clinical translation. Prog Neurobiol. 2014;115:25-44. https://doi. org/10.1016/j.pneurobio.2013.11.003

16. Chen J, Xuan Y, Chen Y, Wu T, Chen L, Guan H, Yang S, He J, Shi $D$, Wang Y. Netrin-1 alleviates subarachnoid haemorrhageinduced brain injury via the PPAR gamma/NF-KB signalling pathway. J Cell Mol Med. 2019;23(3):2256-62. https://doi. org/10.1111/jcmm.14105

17. Zhou Y, Tao T, Liu G, Gao X, Gao Y, Zhuang Z, Lu Y, Wang $\mathrm{H}$, Li W, Wu L, Zhang D, Hang C. TRAF3 mediates neuronal apoptosis in early brain injury following subarachnoid hemorrhage via targeting TAK1-dependent MAPKs and NFKB pathways. Cell Death Dis. 2021;12(1):10. https://doi. org/10.1038/s41419-020-03278-z

18. Kang DH, Choi BY, Lee SH, Kho AR, Jeong JH, Hong DK, Kang BS, Park MK, Song HK, Choi HC, Lim MS, Suh SW. Effects of cerebrolysin on hippocampal neuronal death after pilocarpine-induced seizure. Front Neurosci. 2020;14:568813. https://doi.org/10.3389/ fnins.2020.568813

19. DeBoer SR, Hubbard R, Mersha M, Pinilla Monsalve G, Winter S, Zeiler SR. Enhanced spontaneous motor recovery after stroke in mice treated with cerebrolysin. Neurorehabil Neural Repair. 2021;35(6):525-33. https:// doi.org/10.1177/15459683211000734

20. Zhang L, Chopp M, Meier DH, Winter S, Wang L, Szalad A, Lu M, Wei M, Cui Y, Zhang ZG. Sonic hedgehog signaling pathway mediates cerebrolysin-improved neurological function after stroke. Stroke. 2013;44(7):1965-72. https:// doi.org/10.1161/strokeaha.111.000831

21. Yang $Y$, Zhang $Y$, Wang $Z$, Wang $S$, Gao $M$, Xu R, Liang $C$, Zhang $H$. Attenuation of acute phase injury in rat intracranial hemorrhage by cerebrolysin that inhibits brain edema and inflammatory response. Neurochem Res. 2016;41(4):748-57. https://doi.org/10.1007/s11064015-1745-4

22. Muresanu DF, Florian S, Hömberg V, Matula C, von Steinbüchel N, Vos PE, von Wild K, Birle C, Muresanu I, Slavoaca D, Rosu OV, Strilciuc S, Vester J. Efficacy and safety of cerebrolysin in neurorecovery after moderate-severe traumatic brain injury: results from the CAPTAIN II trial. Neurol Sci. 2020;41(5):1171-81. https://doi.org/10.1007/ s10072-019-04181-y

23. Poon W, Matula C, Vos PE, Muresanu DF, von Steinbüchel $\mathrm{N}$, von Wild K, Hömberg V, Wang E, Lee TMC, Strilciuc S, Vester JC. Safety and efficacy of cerebrolysin in acute brain injury and neurorecovery: CAPTAIN I-a randomized, placebo-controlled, double-blind, Asian-Pacific trial. Neurol Sci. 2020;41(2):281-93. https://doi.org/10.1007/ s10072-019-04053-5
24. Muresanu DF, Heiss WD, Hoemberg V, Bajenaru O, Popescu CD, Vester JC, Rahlfs VW, Doppler E, Meier D, Moessler H, Guekht A. Cerebrolysin and Recovery After Stroke (CARS): a randomized, placebo-controlled, double-blind, multicenter trial. Stroke. 2016;47(1):151-9. https://doi.org/10.1161/ strokeaha.115.009416

25. Vandenabeele P, Galluzzi L, Vanden Berghe T, Kroemer G. Molecular mechanisms of necroptosis: an ordered cellular explosion. Nat Rev Mol Cell Biol. 2010;11(10):70014. https://doi.org/10.1038/nrm2970. PubMed PMID: 20823910

26. Chen T, Yang LK, Zhu J, Hang CH, Wang YH. The AMPAR antagonist perampanel regulates neuronal necroptosis via Akt/GSK3 $\beta$ signaling after acute traumatic injury in cortical neurons. CNS Neurol Disord Drug Targets. 2020. https:// doi.org/10.2174/1871527319666201001110937

27. Chen $\mathrm{T}$, Zhu J, Wang $\mathrm{YH}$, Hang $\mathrm{CH}$. Arc silence aggravates traumatic neuronal injury via mGluR1-mediated ER stress and necroptosis. Cell Death Dis. 2020;11(1):4. https://doi. org/10.1038/s41419-019-2198-5

28. Bao Z, Fan L, Zhao L, Xu X, Liu Y, Chao H, Liu N, You Y, Liu $Y$, Wang $X$, Ji J. Silencing of A20 aggravates neuronal death and inflammation after traumatic brain injury: a potential trigger of necroptosis. Front Mol Neurosci. 2019;12:222. https://doi.org/10.3389/fnmol.2019.00222

29. Laird MD, Wakade C, Alleyne CH, Jr., Dhandapani KM. Hemin-induced necroptosis involves glutathione depletion in mouse astrocytes. Free Radic Biol Med. 2008;45(8):110314. https://doi.org/10.1016/j.freeradbiomed.2008.07.003

30. Shen H, Liu C, Zhang D, Yao X, Zhang K, Li H, Chen G. Role for RIP1 in mediating necroptosis in experimental intracerebral hemorrhage model both in vivo and in vitro. Cell Death Dis. 2017;8(3):e2641. https://doi.org/10.1038/cddis.2017.58

31. Zhang $Y$, Li M, Li X, Zhang $H$, Wang L, Wu X, Zhang $H$, Luo Y. Catalytically inactive RIP1 and RIP3 deficiency protect against acute ischemic stroke by inhibiting necroptosis and neuroinflammation. Cell Death Dis. 2020;11(7):565. https://doi.org/10.1038/s41419-020-02770-w

32. Yuan J, Amin P, Ofengeim D. Necroptosis and RIPK1mediated neuroinflammation in CNS diseases. Nat Rev Neurosci. 2019;20(1):19-33. https://doi.org/10.1038/ s41583-018-0093-1

33. Linkermann A, Green DR. Necroptosis. N Engl J Med. 2014;370(5):455-65. https://doi.org/10.1056/ NEJMra1310050

34. Deng S, Sherchan P, Jin P, Huang L, Travis Z, Zhang JH, Gong $Y$, Tang J. Recombinant CCL17 enhances hematoma resolution and activation of CCR4/ERK/Nrf2/CD163 signaling pathway after intracerebral hemorrhage in mice. Neurotherapeutics. 2020;17(4):1940-53. https://doi. org/10.1007/s13311-020-00908-4

35. Chen J, Zhang C, Yan T, Yang L, Wang Y, Shi Z, Li M, Chen Q. Atorvastatin ameliorates early brain injury after subarachnoid hemorrhagevia inhibition of pyroptosisand neuroinflammation. J Cell Physiol. 2021. https://doi.org/10.1002/jcp.30351 
36. Chen JH, Wu T, Xia WY, Shi ZH, Zhang CL, Chen L, Chen QX, Wang YH. An early neuroprotective effect of atorvastatin against subarachnoid hemorrhage. Neural Regen Res. 2020;15(10):1947-54. https://doi.org/10.4103/16735374.280326

37. Li G, Dong Y, Liu D, Zou Z, Hao G, Gao X, Pan P, Liang G. NEK7 Coordinates rapid neuroinflammation after subarachnoid hemorrhage in mice. Front Neurol. 2020;11:551. https:// doi.org/10.3389/fneur.2020.00551

38. Chen J-H, Wu T, Yang L-K, Chen L, Zhu J, Li P-P, Hu X, Wang $\mathrm{Y}-\mathrm{H}$. Protective effects of atorvastatin on cerebral vessel autoregulation in an experimental rabbit model of subarachnoid hemorrhage. Mol Med Rep. 2018;17(1):16519. https://doi.org/10.3892/mmr.2017.8074

39. El-Marasy SA, El Awdan SA, Hassan A, Ahmed-Farid OA, Ogaly HA. Anti-depressant effect of cerebrolysin in reserpine-induced depression in rats: Behavioral, biochemical, molecular and immunohistochemical evidence. Chem Biol Interact. 2021;334:109329. https:// doi.org/10.1016/j.cbi.2020.109329

40. Satou T, Itoh T, Tamai Y, Ohde H, Anderson AJ, Hashimoto S. Neurotrophic effects of FPF-1070 (Cerebrolysin) on cultured neurons from chicken embryo dorsal root ganglia, ciliary ganglia, and sympathetic trunks. J Neural Transm (Vienna). 2000;107(11):1253-62. https://doi.org/10.1007/ s007020070015

41. Guan X, Wang Y, Kai G, Zhao S, Huang T, Li Y, Xu Y, Zhang $L$, Pang T. Cerebrolysin ameliorates focal cerebral ischemia injury through neuroinflammatory inhibition via CREB/ PGC-1 $\alpha$ pathway. Front Pharmacol. 2019;10:1245. https:// doi.org/10.3389/fphar.2019.01245
42. Aguilar-Hernández L, Gómez-Villalobos MJ, Flores G. Cerebrolysin ameliorates prefrontal cortex and hippocampus neural atrophy of spontaneous hypertensive rats with hyperglycemia. Synapse. 2020;74(9):e22156. https://doi.org/10.1002/syn.22156

43. Kim JY, Kim HJ, Choi HS, Park SY, Kim DY. Effects of cerebrolysin ${ }^{\circledR}$ in patients with minimally conscious state after stroke: an observational retrospective clinical study. Front Neurol. 2019;10:803. https://doi.org/10.3389/ fneur.2019.00803

44. Park YK, Yi HJ, Choi KS, Lee YJ, Kim DW, Kwon SM. Cerebrolysin for the treatment of aneurysmal subarachnoid hemorrhage in adults: a retrospective chart review. Adv Ther. 2018;35(12):2224-35. https://doi.org/10.1007/ s12325-018-0832-8

45. Woo PYM, Ho JWK, Ko NMW, Li RPT, Jian L, Chu ACH, Kwan MCL, Chan Y, Wong AKS, Wong HT, Chan KY, Kwok JCK. Randomized, placebo-controlled, double-blind, pilot trial to investigate safety and efficacy of Cerebrolysin in patients with aneurysmal subarachnoid hemorrhage. BMC Neurol. 2020;20(1):401. https://doi.org/10.1186/s12883020-01908-9

46. Lu J, Sun Z, Fang Y, Zheng J, Xu S, Xu W, Shi L, MeiS, Wu H, Liang F, Zhang J. Melatonin suppresses microglial necroptosis by regulating deubiquitinating enzyme $\mathrm{A} 20$ after intracerebral hemorrhage. Front Immunol. 2019;10:1360. https://doi. org/10.3389/fimmu.2019.01360

47. Chen C, Zhou F, Zeng L, Jiang Z, Hu Z. Methylene blue offers neuroprotection after intracerebral hemorrhage in rats through the PI3K/Akt/GSK3 $\beta$ signaling pathway. J Cell Physiol. 2019;234(4):5304-18. https://doi.org/10.1002/ jcp. 27339 